\title{
Conhecendo a pesca artesanal em Tramandaí e Imbé - RS: Distribuição espacial e desafios
}

Getting to know the artisan fishing in Tramandaí and Imbé - RS:

Space distribution and challenges

Abraão Martins Terceiro

Universidade Federal do Rio Grande

abraaoterceiro@hotmail.com

\begin{abstract}
Resumo
O trabalho aborda como tema a pesca artesanal e apresenta como principais objetivos, à caracterização da atividade nos municipios de Tramandai e Imbé, localizados no Estado do Rio Grande do Sul, à distribuição espacial e os desafios enfrentados para que ocorram as pescarias nessa região. A pesquisa se justifica pelo grande número de pescadores existentes na área de estudo e pela importância econômica da atividade, mapeando através do conhecimento popular as áreas de maior valor para a pesca, as principais espécies existentes e os principais recursos e instrumentos utilizados na captura do pescado.
\end{abstract}

Palavras-chave: Pesca artesanal; Territórios; Conflito

\section{Abstract}

The work deals with the theme artisanal fisheries and has as main objective, the characterization of the activity in the municipalities of Tramandai and Imbé, located in the State of Rio Grande do Sul, the spatial distribution and the challenges to occur fisheries in this region. The research is justified by the large number of fishermen in the study area and the economic importance of the activity, mapping through popular knowledge areas of greatest value for fishing, the main existing species and the main features and instruments used in fish capture.

Keywords: Artisanal fishing; Territories; Conflicts 


\section{Introdução}

De acordo com Diegues (1973), os pescadores artesanais são aqueles que, na captura e desembarque de toda classe de espécies aquáticas, trabalham sozinhos e/ou utilizam mão de obra familiar ou não assalariada, explorando ambientes ecológicos continentais ou localizados próximos à costa, pois em geral a embarcação e aparelhagem utilizadas para tal fim possuem pouca autonomia.

A definição segundo a lei 11.959/2009, diz que a pesca artesanal é aquela praticada diretamente por pescador profissional, de forma autônoma ou em regime de economia familiar, com meios de produção próprios ou mediante contrato de parceria, desembarcado, podendo utilizar embarcações de pequeno porte (BRASIL, 2009).

De acordo com tal definição, Walter \& Anello (2012) salientam que os pescadores artesanais demandam um ambiente íntegro, juntamente com o acesso tanto às áreas de pesca como áreas em terra para sua reprodução social.

A área de desenvolvimento da pesquisa abrangeu Tramandaí e Imbé, dois municípios costeiros situados no Estado do Rio Grande do Sul, que apresentam grande desenvolvimento da atividade pesqueira, juntamente com diversos problemas que ameaçam sua reprodução social pelas comunidades tradicionais locais.

De acordo com Cotrim \& Miguel (2007), existe na região da planície costeira do RS, onde estão localizados os municípios de Tramandaí e Imbé, uma grande quantidade de famílias que retiram da pesca seu sustento.

Segundo o Ministério da Pesca e Aquicultura, por meio do Registro Geral de Pesca (RGP), em 2011, havia em Tramandaí cerca de 869 pescadores artesanais e em Imbé 245.

A região da planície costeira onde se localizam esses dois municípios, apresentam condições geográficas estratégicas para o desenvolvimento da pesca, possuindo um aporte hídrico significativo para a atividade, devido à presença do mar e do rio Tramandaí, com a existência de várias lagoas e formação de estuário.

A laguna de Tramandaí não é profunda, tendo praias arenosas ao sul, banhados em sua margem leste e vegetação de restingas a sudoeste. Além desta existem também no município as lagoas do Armazém e da Custódia todas elas apresentando características estuarinas (SARAIVA \& PUPER, 1985).

Essas condições ambientais facilitam o aparecimento do pescado na região. Segundo Macedo et al. (2000), os estuários, que representam locais de transição entre as águas continentais e marinhas, conhecidos por sua alta fertilidade e como excelentes produtores e exportadores de matéria orgânica funcionam como verdadeiros berçários naturais de muitas espécies marinhas, estuarinas e de água doce, sendo vitais na sustentabilidade das populações ribeirinhas que fazem uso de seus recursos naturais.

Os principais objetivos da pesquisa foram quanto à caracterização da pesca artesanal nos municípios de Tramandaí e Imbé, juntamente com a identificação dos principais problemas que acompanham a atividade na região.

Diante do grande número de pescadores na região e da prática intensa da atividade pesqueira, é que se justifica o desenvolvimento dessa pesquisa, facilitando a identificação das principais áreas de pesca, os tipos de pesca, as principais espécies capturadas, e os principais problemas enfrentados para a realização das pescarias.

\section{Metodologia}

A metodologia desenvolvida para a formulação da pesquisa ocorreu basicamente após a delimitação da área de estudo, seguida dos procedimentos tomados para a realização do trabalho, que foram divididos em quatro momentos: levantamento bibliográfico, oficinas participativas, organização e análise dos dados. 
Cada momento da pesquisa seguiu orientações da literatura tomando como base o referencial teórico abordado no estudo, tanto para a observação do campo, quanto aos procedimentos realizados na aplicação das oficinas participativas.

\section{1 Área de estudo}

A área de estudo (figura 1), compreende dois municípios costeiros, vizinhos, situados no litoral Norte do Estado do Rio Grande do Sul, com uma distância de 118 km da Capital Porto Alegre. Tramandaí apresenta segundo o Censo do IBGE (2010), uma população de 41.585 habitantes e uma área de 144,408 km², com localização geográfica de Latitude: $30^{\circ} 00^{\prime} 38^{\prime}$ ' Sul e Longitude: 50 09' 08', Oeste, e Imbé, com 17.670 habitantes, ocupando 39,395 km² de extensão territorial apresentando as coordenadas de Latitude: $29^{\circ} 58^{\prime} 31^{\prime \prime}$ Sul e Longitude $50^{\circ} 07^{\prime} 41^{\prime \prime}$ Oeste.

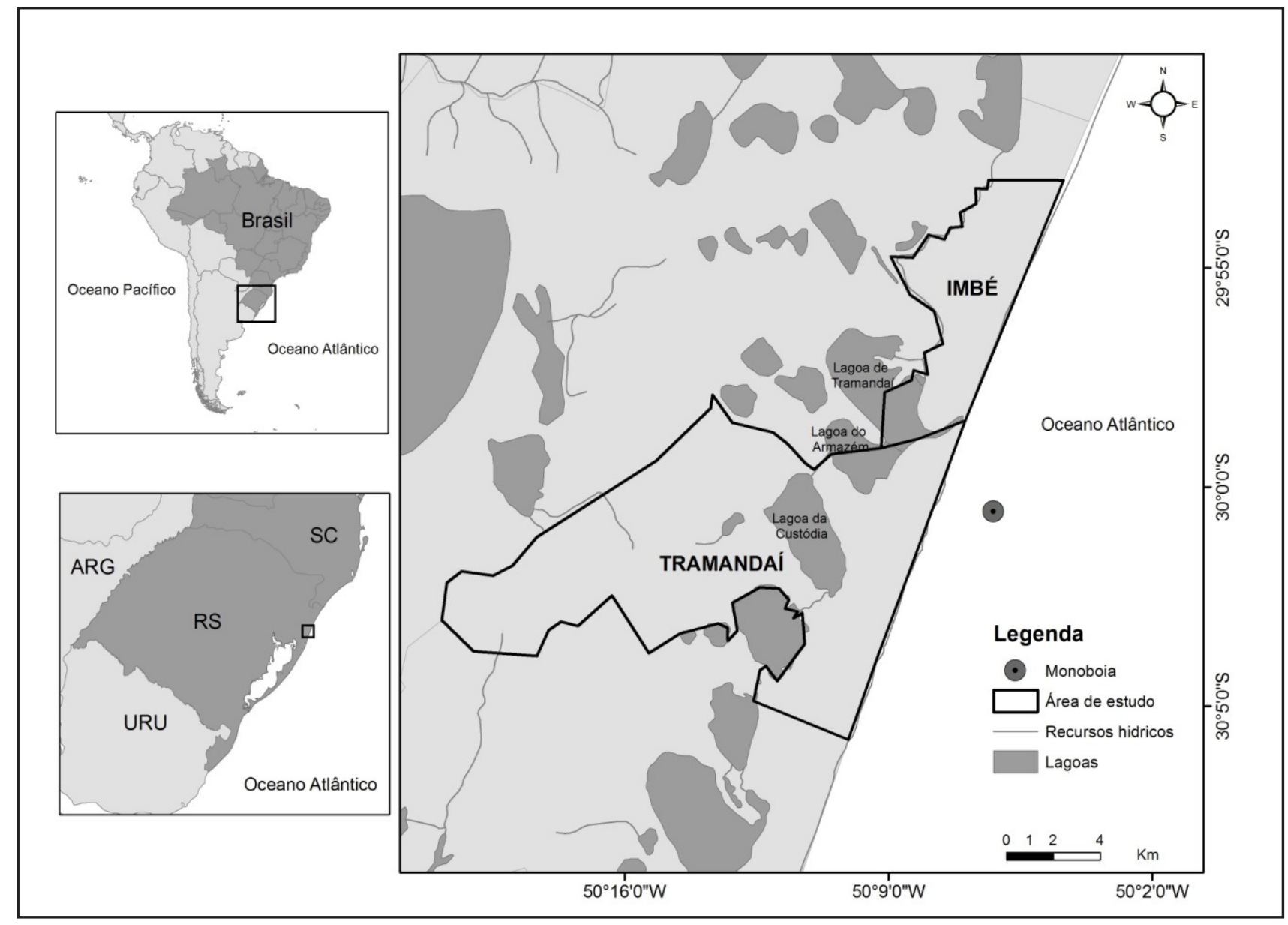

Figura 1 - Mapa de localização da área de estudo

\subsection{Procedimentos de pesquisa}

\subsubsection{Levantamento bibliográfico}

O levantamento bibliográfico foi o primeiro procedimento tomado a partir da escolha do tema e da delimitação da área de estudo. Esse procedimento se estendeu por toda a pesquisa até sua conclusão, seu principal objetivo foi a montagem de um banco de dados, contendo todas as informações possíveis em relação a atividade pesqueira na região. 
Nessa etapa, foi adquirido o maior número de informações possíveis em relação à área de estudo, atividade pesqueira, legislação, levantamento de artigos científicos e trabalhos técnicos, entre outras fontes de interesse, que abordassem as necessidades e expectativas da pesquisa.

Para o levantamento de informações na literatura, procuramos alguns trabalhos de autores que tratam especificadamente do tema pesqueiro na região, isso ocorreu devido à necessidade de comparar e apropriar a veracidade das informações coletadas em campo durante a pesquisa.

Foi feita uma visita ao Campus da Universidade Federal do Rio Grande do Sul, onde procuramos professores e demais pesquisadores da região, para fins de atender também a busca de informações sobre a pesca praticada nos municípios de Tramandaí e Imbé assim como o reconhecimento geral do campo.

\subsubsection{Oficinas participativas}

Esse momento consistiu com a aplicação de duas oficinas previamente agendadas com pescadores artesanais de Tramandaí e Imbé, no período de 12 a 15 de fevereiro de 2014, diferenciando em grupos, de acordo com o ambiente de pesca, podendo ser marinho ou lagunar/estuarino.

As oficinas (figura 2) tiveram o objetivo central de identificar os principais pontos de prática da atividade pesqueira, os instrumentos utilizados, as espécies capturadas, os costumes desse grupo social e os problemas enfrentados para a realização da pesca.

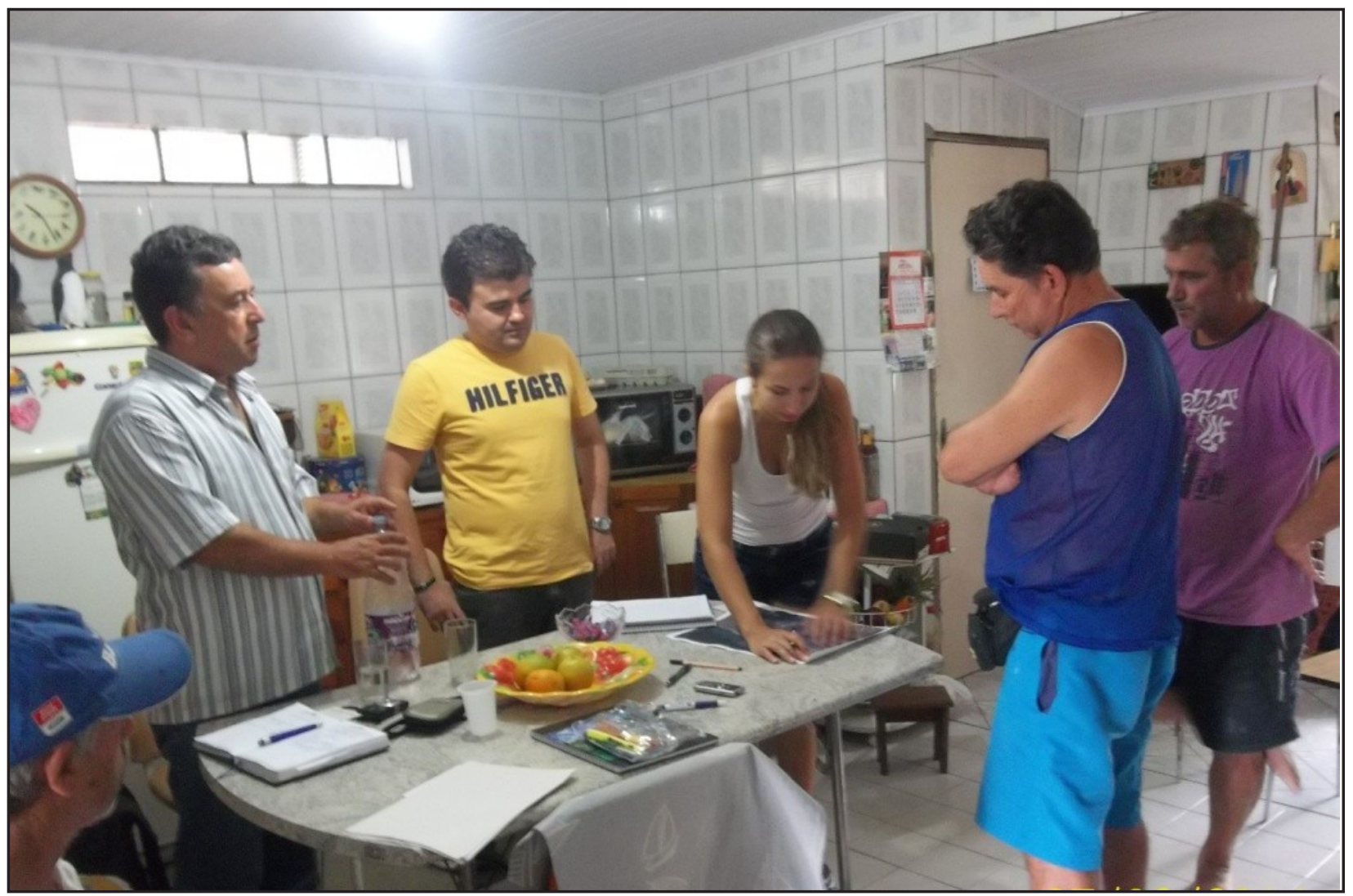

Figura - 2 Oficinas participativas

Foram agendadas as visitas para a aplicação das oficinas, com o auxílio de um funcionário pertencente ao escritório da EMATER em Imbé. Logo após o contato, ocorreu a delimitação dos grupos, onde se teve a clareza de que, 
para escolher os participantes, deveria se considerar a indicação da comunidade, da EMATER, que apresenta grande conhecimento da região e dos representantes do Fórum dos Pescadores do Litoral Norte do Rio Grande do Sul, como estratégia de adquirir pessoas que fornecessem subsídios a componente qualitativa da pesquisa.

Foram realizadas duas oficinas. Uma na parte da manhã ocorrida numa casa situada no bairro Mariluz, localizado no município de Imbé, com a presença de doze pescadores artesanais, entre eles, homens e mulheres que praticam a atividade. Sendo estes de atuação na área marinha e lagunar/estuarina de toda a região de Tramandaí e Imbé.

A outra oficina foi realizada na parte da tarde, com um grupo bem pequeno de apenas três pescadores, situados ao centro do município de Imbé, onde também realizavam a pesca tanto na parte marinha quanto estuarina.

Passamos uma lista de frequência nas duas oficinas, para poder estabelecer o conhecimento quanto aos nomes das pessoas presentes e manter o controle quanto à identificação dos participantes. Tiramos fotografias para registrar o evento e os produtos finais resultados da prática da atividade.

Uma das atividades realizadas, de relevância para a pesquisa, foi a elaboração de mapas mentais, tendo a divisão de grupos entre pescadores de área marinha e da região lagunar/estuarina. Cada grupo preencheu o mapa com as informações quanto à arte de pesca praticada, áreas de pesca, petrechos utilizados, principais espécies capturadas.

\subsubsection{Organização e análise dos dados}

Todos os dados foram catalogados de acordo com os interesses propostos na pesquisa. As oficinas foram organizadas num diário de campo, tornando mais fácil a visualização das observações feitas durante os procedimentos aplicados.

No diário de campo, foi possível anotar todas as observações realizadas durante as visitas nos municípios de Tramandaí e Imbé. Nele continham as informações das principais espécies capturadas, o nome dos pescadores que participaram das oficinas, endereços e contatos importantes, como o da colônia de pescadores e do escritório da EMBRAPA.

Foi possível também anotar as observações feitas em campo ao presenciar as atividades de pesca, como os equipamentos e materiais utilizados pelos pescadores, áreas de trabalho, jornada de pesca e de campo para a coleta das informações.

Os resultados permitiram elaborar com os pescadores mapas mentais, sendo sistematizados posteriormente de forma a gerar um único mapa, respeitando a coleta de informações das oficinas realizadas. A sistematização, ocorreu com a organização das informações coletadas durante o campo.

Para a confecção dos mapas mentais, observamos como os pescadores organizaram no mapa as informações, depois juntamos todas as informações contidas no final das oficinas em um único mapa e apresentamos a eles para verificar a veracidade dos dados organizados.

\section{Resultados e discussão}

\subsection{A pesca artesanal}

De acordo com as oficinas aplicadas com os pescadores artesanais dessa região, observa-se que a pesca se divide em marinha e estuarina. $\mathrm{O}$ uso de petrechos e de técnicas aplicadas para as pescarias se diferem de acordo com o ambiente. 
Cotrim \& Miguel (2007) relatam que o processo de especialização da atividade da pesca se intensificou em Tramandaí. Segundo eles, existem diversas combinações entre as relações sociais do grupo dos pescadores artesanais e o ambiente.

Estas interações geraram seis sistemas de produção na pesca dentro de duas zonas, que o autor denomina como agroecológicas. Na zona agroecológica do mar foram reconhecidos os sistemas de produção na pesca $d o c a b o$, da tarrafa peixe e do bote. Na zona agroecológica estuarina foram identificados os sistemas de produção na pesca do aviãozinho, da tarrafa camarão e do comércio (COTRIM \& MIGUEL 2007).

Durante as oficinas os pescadores artesanais relataram que os principais petrechos utilizados na realização da pesca na praia, são através da utilização da tarrafa e pela prática da pesca com cabo. A pesca mais afastada da costa é realizada através de uso de botes e em menor frequência quando comparada com as demais.

Cotrim \& Miguel (2007) relatam que as duras características do mar da região, onde existem fortes correntes marítimas, não possibilitaram o desenvolvimento de uma pesca de alto mar, levando os pescadores artesanais a uma adaptação e especialização.

Desta forma, alguns pescadores começaram a explorar as lagoas costeiras, outros optaram pela exploração do estuário da laguna de Tramandaí e muitos se espalharam pela longa beira de praia da faixa costeira. Segundo os pescadores, isso ocorre devido aos poucos recursos disponíveis para a realização desse tipo de pescaria e também pelas dificuldades de acesso as regiões.

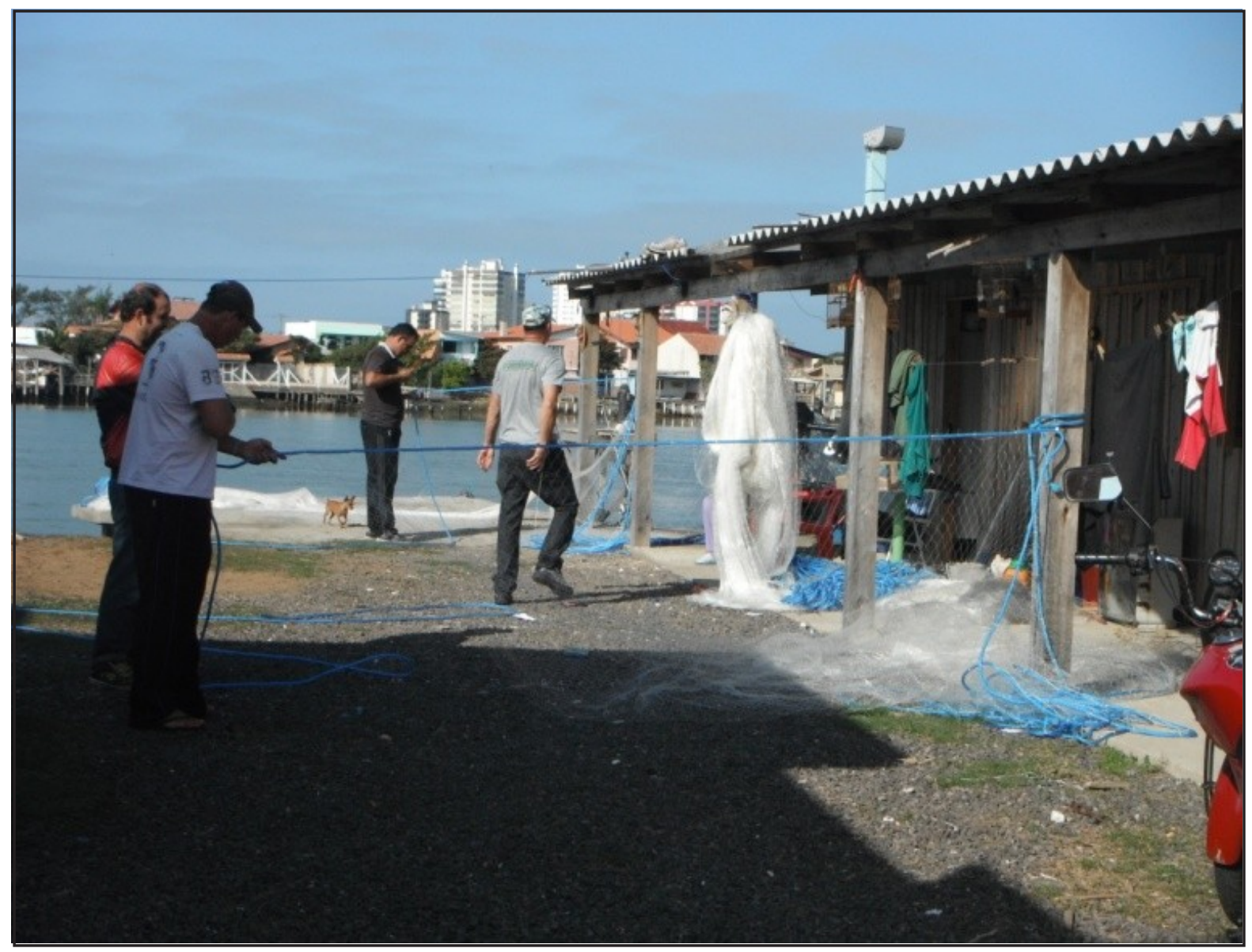

Figura 3 - Pescadores e seus petrechos de pesca 
Os pescadores artesanais relatam que os principais petrechos (figura 3) utilizados na área estuarina são: a tarrafa e as redes firmadas nas balizas de pesca. As pescarias ocorrem com maior frequência nas lagoas da Custódia, Armazém e Tramandaí.

Segundo eles, a pesca de tarrafa, é feita com uma rede circular que possui uma corda presa a ela, onde o pescador joga a rede na água e a puxa pela corda, recolhendo o produto da pescaria.

Relatam que a pesca nas balizas ocorre com redes presas em estacas firmadas dentro da lagoa, onde existe um rodízio de uso dessas estacas até a boca do rio Tramandaí.

$\mathrm{Na}$ literatura, vemos que, as principais espécies de peixes capturadas pelos pescadores são a tainha (Mugil platanus) e o bagre (Netuna barba). Os principais crustáceos que utilizam a lagoa para seu desenvolvimento são o camarão rosa (Farfantepenaeus paulensis) e o siri (Callinectes sapidus) (COTRIM \& MIGUEL, 2007).

Durante a aplicação das oficinas os pescadores forneceram os dados referentes às principais espécies capturadas. Sendo no estuário: a tainha, o bagre, a corvina e o linguado. E na praia: anchova, bagre, papa-terra, bagre branco, peixe espada, cação anjo, peixe rei, corvina, robalo flecha, garoupa, robalo peba, linguado, sardinha, miraguaia, tubarão martelo, tainha.

Em relação à maneira, área e período aos quais os pescadores da região de Tramandaí e Imbé realizam a pesca, existe na legislação estadual e municipal, diretrizes que servem para lhes auxiliar quanto à prática de suas atividades.

No município de Imbé, existe a lei municipal $\mathrm{n}^{\circ} 1328$, que estabelece as áreas de surf e de pesca na orla da praia ao longo do ano, orientando aos usuários da praia sobre as regiões permitidas a prática de suas atividades.

O decreto estadual n $\mathrm{n}^{\circ} 49.245$ de 18/06/2012, dispõe sobre a demarcação das áreas de lazer, pesca e recreação em municípios de orla marítima, lacustre ou fluvial no Rio Grande do Sul, que segundo o decreto o objetivo é garantir a manutenção das atividades de uso dos espaços de forma a oferecer segurança a todos os frequentadores desses ambientes.

Em relação à sustentabilidade da atividade da pesca, os pescadores a partir da aplicação da Instrução Normativa do MMA de $\mathrm{n}^{\circ} 17$ de 2004 foram submetidos a regras quanto aos critérios para a realização da pesca na Bacia do rio Tramandaí. Tal instrução normativa foi substituída pela IN 07/2013, apresentando a finalidade de manter a atividade e de proteger as espécies contra medidas de pesca predatórias.

Cotrim \& Miguel (2007) relatam que se consolidou uma estratégia local de comercialização do pescado em Tramandaí baseada nas características de baixa captura por unidade de produção, conservação a frio individualizada e mercado consumidor próximo. Segundo eles, foi gerada uma dinâmica local de comércio de peixe, onde existiu o processamento de pescado realizado de forma artesanal e a comercialização direta ao consumidor.

De acordo com Perucchi et al. (2012), com o objetivo de realizar um diálogo integrado, sobre os problemas que envolvem a pesca artesanal no Litoral Norte do Rio Grande do Sul, em 2003 foi criado o Fórum de Pesca do Litoral Norte.

Diversos atores participam do Fórum, além das associações, sindicatos e colônias de pescadores, que articulam a presença dos pescadores nas reuniões. Há também a participação governamental, com a presença do IBAMA, Secretaria do Desenvolvimento Rural/ SDR por meio do Departamento de Pesca, Aquicultura, Quilombolas e Indígenas - DEPAQUI, EMATER, Ministério da Pesca e Aquicultura/ MPA, Universidades entre outros.

Perucchi et al. (2012), afirmam ainda que dentre as questões identificadas nos encontros com os pescadores, sobre as quais já existe um trabalho de articulação e encaminhamento no âmbito do Fórum do Litoral Norte do Rio Grande do Sul, destaca-se a situação do derramamento de óleo. 
De acordo com isso, podemos observar nesse sentido que os pescadores artesanais dependem do ambiente para realizarem suas atividades, portanto necessitam manter a integridade da qualidade ambiental.

Em relação à privatização de áreas de direitos de uso público, caracteriza-se nesse aspecto a partir da ocupação por implantação e funcionamento do empreendimento petrolífero em áreas de uso comum de propriedade da União, impedindo o acesso público a determinadas áreas.

\subsection{A pesca no ambiente estuarino}

Durante as oficinas verificou-se que há pescadores que atuam no ambiente estuarino, há aqueles que atuam no ambiente marinho e outros que atuam nos dois.

Entretanto, a pesca estuarina é a mais frequente e mais relevante aos pescadores artesanais. Isso se aplica devido à facilidade do acesso ao meio e também por ser menos perigosa quando comparada às condições físicas do ambiente lagunar ao ambiente marinho.

De acordo com Cotrim \& Miguel (2007), as lagoas costeiras nesta área apresentam profundidade variando entre um a dois metros, o que permite uma penetração da luz solar em toda a sua coluna d'água. Sendo esta situação favorável ao desenvolvimento das algas, que são a base alimentar para peixes e crustáceos, tornando essa região em berçários naturais para as espécies.

Cotrim \& Miguel (2007), ainda afirmam que estas circunstâncias de pouca profundidade e ambiente estuarino possibilitaram a formação de banhados nas margens das lagoas, que são ambientes ricos em matéria orgânica e que fazem o papel de segurar o excesso de água nas épocas de chuvas e liberar nas épocas de secas. Nos banhados existe a formação vegetal complexa de juncais e gramíneas que são essenciais na cadeia alimentar das espécies lacustres.

Dessa maneira, observou-se também nas oficinas, que estes conjuntos de condições determinam que estas lagoas sejam consideradas como locais de excelência para o desenvolvimento da fauna típica de estuário, o que criou naturalmente um ambiente rico em recursos pesqueiros.

Durante as oficinas, os pescadores relataram que as espécies de peixes capturados na laguna de Tramandaí, concentram-se em determinadas áreas. Geralmente são as áreas onde se localizam as balizas de pesca dentro da laguna e também nos canais e nas bocas dos rios que deságuam no complexo estuarino.

O camarão é também um recurso importante a ser capturado na pesca estuarina. As principais áreas de captura localizadas pelos pescadores no momento das oficinas são as áreas que abrangem a lagoa do Armazém, a lagoa da Custódia e o canal que liga as duas, denominado de Arroio Manuel.

Destaca-se que essas duas lagoas encontram-se bastante próximas do terminal terrestre da TRANSPETRO, sendo a lagoa do Armazém, a que apresenta maior proximidade ao empreendimento.

A lagoa do Armazém é ligada a lagoa de Tramandaí, que também apresenta o camarão como recurso pesqueiro. Essas regiões, por serem interligadas, suas águas apresentam características bastante semelhantes, sendo todas expostas também ao perigo oferecido pela atividade do petróleo.

Existem determinados locais na Laguna de Tramandaí onde os pescadores utilizam certos espaços para fazer uma espécie de armazém, onde guardam seus utensílios de pesca.

Essas áreas são chamadas por eles de sarilhos (figura 4) e apresentam uma importante significância dentro dos espaços pesqueiros, enfrentando fortes disputas por áreas com as casas e marinas construídas ao longo das margens do estuário. 


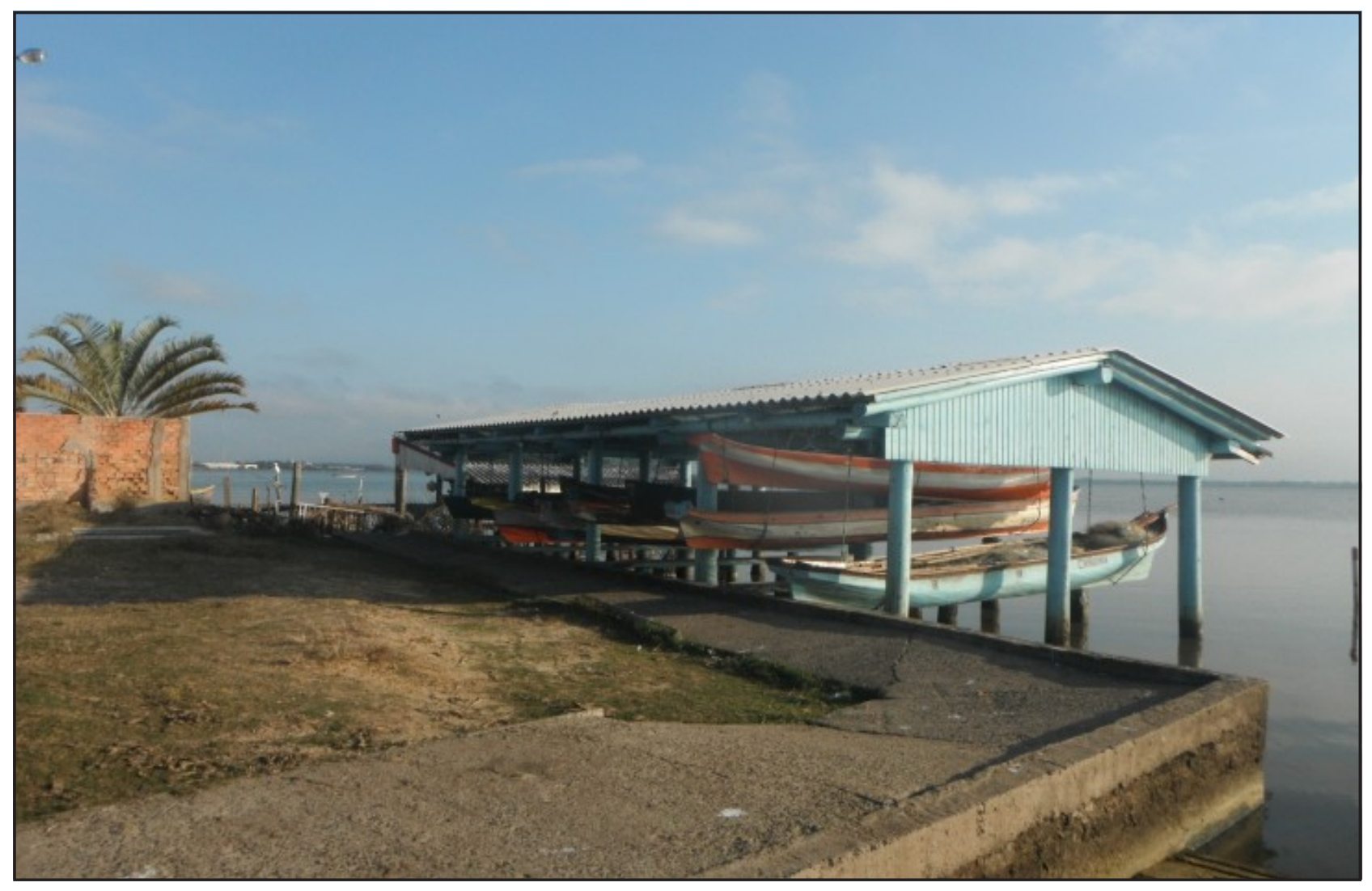

Figura 4 - O sarilho

\subsection{A pesca no ambiente marinho}

Em relação à pesca realizada no ambiente marítimo, faz-se necessário resgatar a importância da beira da praia como local de pesca, dado que tanto o uso de tarrafas como a pesca de cabo são mais frequentes e a praia é o local de sua realização.

Contudo, o uso da praia é de interesse de vários atores sociais que usufruem desse ambiente para o desenvolvimento de inúmeras atividades, provocando uma série de conflitos.

Esses grupos sociais presentes na faixa de praia disputam por espaços com os pescadores, tornando ainda mais difícil a prática de suas atividades e dando margens a ocorrências de conflitos para além da atividade petrolífera.

No depoimento dos pescadores artesanais, a atividade do petróleo traz menos danos à pesca, quando comparadas com as disputas de território ocorridas no período do veraneio pelos turistas e também pelas áreas de surf demarcadas no local.

Assim, a vulnerabilidade da pesca e dos pescadores é grande frente ao empreendimento petrolífero, porém não está isolada. Nota-se que outros problemas podem acompanhar a presença da atividade na região.

De acordo com as oficinas, foi possível observar que esses conflitos, podem ocorrer, em relação às atividades do surf praticado por moradores e turistas na região, a partir disso, deu-se a criação da Lei Municipal nº 1328 de 12 de setembro de 2011, que estabelece as áreas de surf e de pesca, limitando as atividades dos pescadores e quebrando um elo histórico quanto à realização das pescarias na região. Para os pescadores, tal lei viola seus direitos, inibindo e descaracterizando a atividade pesqueira realizada na praia. 


\subsection{Mapa mental das áreas de pesca}

O mapa mental apresenta as principais espécies capturadas pelos pescadores artesanais, tanto na região marinha, quanto na estuarina, descrevendo a partir disso, a similaridade e as preferências pelo tipo de pescado.

Apresentam ainda toda a configuração da pesca nos municípios costeiros de Tramandaí e Imbé, com a principal arte de pesca e sua distribuição ao longo da área de estudo.

Mostram também as áreas com os principais conflitos, sendo esses, ligados ás atividades de surf, circulação do petróleo, veraneio, ocupações inadequadas e pesca esportiva.

Esses fatores são os responsáveis pela caracterização do cenário pesqueiro da região e podem ser observados de acordo com o produto gerado (figura 5), através da aplicação das oficinas participativas realizadas com os pescadores artesanais.

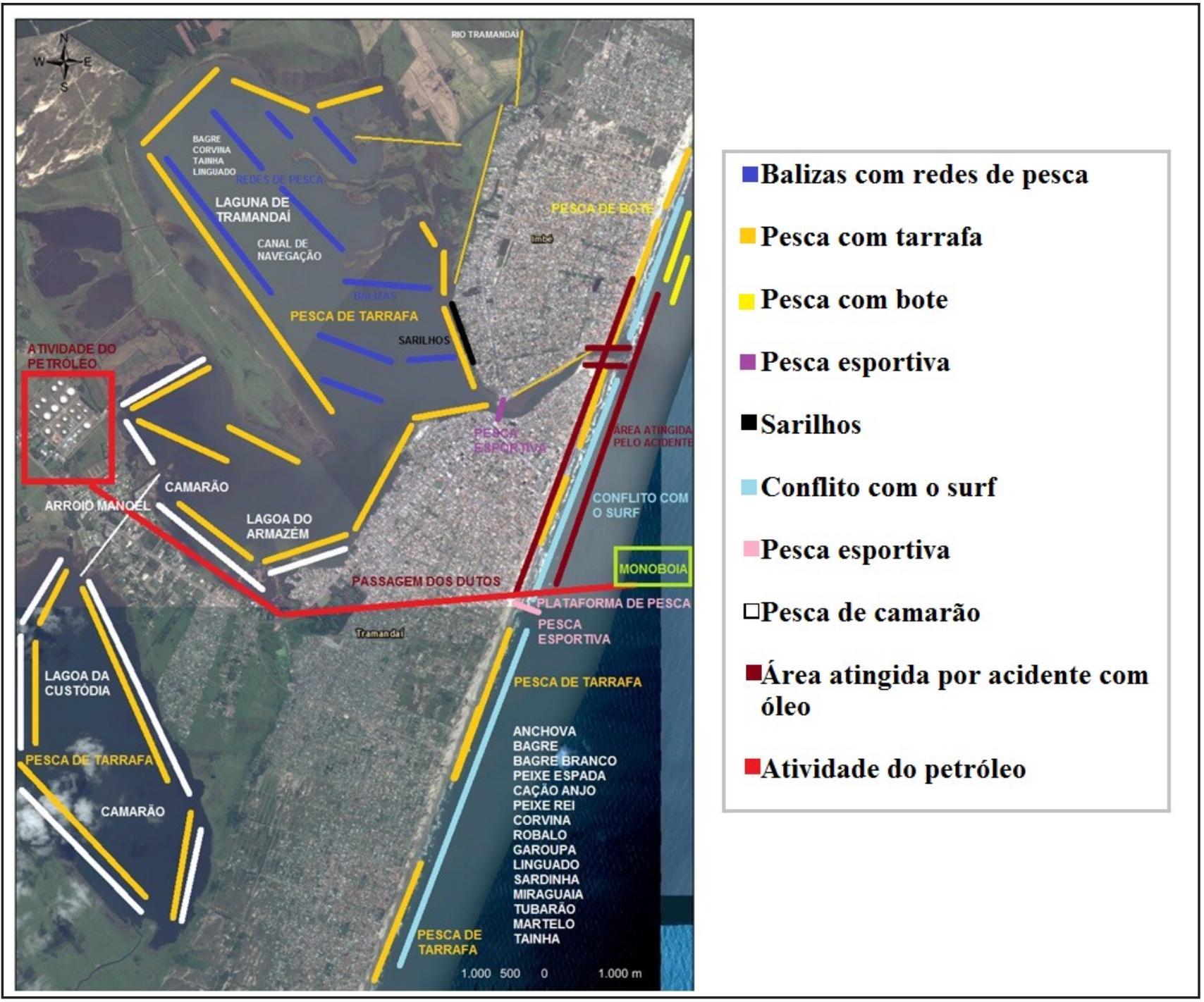

Figura 5 - Mapa mental das áreas de pesca em Tramandaí e Imbé

\section{Conclusões}

Os resultados apresentados na pesquisa mostram que é preciso que haja por parte das instituições e órgãos públicos uma maior atenção quanto à atividade pesqueira nos municípios de Tramandaí e Imbé. 
Existe o risco de acidentes com derramamento de óleo, pesca predatória, práticas de atividades de risco e ocupação ilegal de áreas na região, com isso, é preciso que ocorra mais fiscalização por parte das autoridades competentes e que sejam desenvolvidos programas de educação ambiental para a conscientização quanto à importância dessa área de estudo para a manutenção da atividade pesqueira tradicional.

\section{Agradecimentos}

Agradeço ao Laboratório de Gerenciamento Costeiro da Universidade Federal do Rio Grande pelo apoio logístico para a realização dessa pesquisa, a equipe da UNIASSELVI pela oportunidade de expor tal pesquisa na perspectiva da gestão e educação ambiental através da pós-graduação.

\section{Referências}

BRASIL. 2004. Ministério do Meio Ambiente. Instrução Normativa MMA no 17, de 17 de outubro de 2004. p. 6.

BRASIL. 2009. Lei no 11.959, de 29/06/2009, que “Dispõe sobre a Política Nacional de Desenvolvimento Sustentável da Aquicultura e da Pesca, regula as atividades pesqueiras".

BRASIL. 2013. Ministério do Meio Ambiente. Instrução Normativa MMA noำ 07/2013.

BRASIL. Ministério do Planejamento, Orçamento e Gestão. Instituto Brasileiro de Geografia e Estatística. Contagem Populacional. Disponível em: http://www.cidades.ibge.gov.br/xtras/home.php Censo IBGE 2010. Acesso: 03/03/2014.

COTRIM, D. S.; MIGUEL, L. de A. IN: Eisforia, ano 5, volume 5, número 2. Dezembro 2007, PPG Agroecossistemas/ UFSC, Florianópolis. p. 136-160.

DIEGUES, A. C. Pesca e marginalização no litoral paulista. 1973. 187 f. Dissertação (Mestrado) - NUPAUB; CEMAR, Universidade de São Paulo, São Paulo, 1973.

ESTADO DO RIO GRANDE DO SUL. 2012. Assembleia Legislativa. DECRETO № 49.245, DE 18 DE JUNHO DE 2012. (publicado no DOE n.. 117 , de 19 de junho de 2012).

IMBÉ. Lei municipal no1328 de 12 de setembro de 2011. Demarca as áreas de surf e pesca no município de Imbé e dá outras providências.

MACÊDO, S. J.; FLORES MONTES, M. J.; LINS, I. C. Cap. 2. Características abióticas da área. In: BARROS, H. M.; ESKINAZI-LEÇA, E.; MACÊDO, S. J.; LIMA, T. (Eds). Gerenciamento Participativo de Estuários e manguezais. Ed. Universitária da UFPE, Recife, 2000. p. 7 - 25.

PERUCCHI, L. C.; KUBO, R. R.; COELHO-DE-SOUZA, G. Articulação e encaminhamento das questões da pesca artesanal: Uma análise do Fórum da Pesca do Litoral Norte do Rio Grande do Sul. Revista de Gestão Costeira. Vol. 12. №4, 2013. p. 499 - 508.

WALTER, T.; ANELLO, L. de F. S. A EDUCAÇÃO AMBIENTAL ENQUANTO MEDIDA MITIGADORA E COMPENSATÓRIA: Uma reflexão sobre os conceitos intrínsecos na relação com o Licenciamento Ambiental de Petróleo e Gás tendo a pesca artesanal como contexto. Ambiente \& Educação, vol. 17(1), 2012. p.73- 98 . 